\title{
Effects of Nutrients, Mainly from Mediterranean Dietary Foods, on Mesenchymal Stem Derived Cells: Growth or Differentiation
}

\section{Sergio Ammendola ${ }^{1}$, Rossana Cocchiola ${ }^{2}$, Mariangela Lopreiato ${ }^{2}$ and Anna Scotto d' Abusco ${ }^{2 *}$}

${ }^{1}$ Ambiotec S.A.S. Via Appia Nord 47, 04012 Cisterna di Latina (LT), Italy

${ }^{2}$ Department of Biochemical Sciences, Sapienza University of Roma, P.le A. Moro 5, 00185 Roma, Italy

\begin{abstract}
During the last decade the interest for the mesenchymal cells is growing due to their possible uses in therapies to treat certain degenerative pathologies. Mesenchymal stem cells have been found in the bone marrow and they have been shown to be responsible for bone repair and fat cells production. Mesenchymal stromal cells can be obtained from a wide variety of tissues in addition to bone marrow and can differentiate into many other cell types. The study of cell differentiation and programming provides new models for drug discovery and cell therapy that now overcomes gene therapy. Senescence, cancer development and degenerative diseases depend on mesenchymal cells contribution to tissue homeostasis. On the other hand, diet and life style are included among risk factors, which can contribute to the success of pharmacological treatments. This review focuses on nutrients from Mediterranean diet and supplements, which have been shown to influence mesenchymal stem cells and cells derived from them. Dietary intake of nutrients impairs both in vitro and in vivo observations, this review aims to gather the results about the effects of food compounds on mesenchymal cells from which adipocytes and osteoblasts derive. Amino acids and proteins, carbohydrates, lipids, fatty acids and vegetable secondary metabolites, differently act on mesenchymal cells bearing on modulation of gene expression and controlling the fate of cell lineages. Remarkable, the analysis of literature shows that the main effect of nutrients on mesenchymal cells is the stimulation of transcription factors which address the cells toward proliferation or differentiation. For instance, carbohydrates, simple or complex, and lipids appear to stimulate the PPAR receptors, whereas proteins and amino acids result to act on the MTOR system and they can also stimulate the MyoD-1 transcription factor and cooperating proteins. In conclusion, nutrients can promote cell growth and differentiation of mesenchymal cells.
\end{abstract}

\section{Publication History:} Received: March 24, 2018

Accepted: June 25, 2018

Published: June 27, 2018

\section{Keywords:}

Mesenchymal cells, Mediterranean foods, Cell growth, Cell differentiation, mTOR pathway, PPAR $\gamma$ pathway, Short Chain Fatty Acids.

\section{Introduction}

Mesenchymal stem cells (MSCs) are multipotent stromal cells, in vivo isolated by Bone Marrow (BM) that can differentiate into osteoblasts (bone cells), chondrocytes (cartilage cells) and adipocytes (adipose tissue cells) (Figure 1) [1]. Moreover, mesenchymal stromal cells have been described, those cells may originate from several tissuespecific multipotent precursors, that are present in native tissues, and show diverse degrees of plasticity and self-renewal ability $[2,3]$. These cells, depending on native tissue, can differentiate in osteoblasts and myocytes, under suitable stimulations. Molecules present in foods can interfere with cell differentiation and stimulation. Foods are complex matrix of healthful nutrients and unhealthful anti-nutrients, able to contrast the absorption of healthful compounds, thus, a meal should contain a sufficient amount of synergic nutrients. A food that results efficacious to promote health or prevent damages is considered a functional food. Nutrients in a meal may modulate the expression of some genes (nutrigenomics), on the other hands the body, including microbiota, may modify nutrients (nutrigenetics).

We are interested in cellular models suitable for nutrigenomic studies. Previously we analyzed the effects of nutraceutical compositions in osteoblast cells, studying the gene expression level of several genes by Real Time-PCR (RT-PCR).

Functional nutrients or nutraceuticals can modulate gene expression and chromatin architecture, acting on regulation of key modulators such as the mTOR system, PPAR receptors and HDACs and NADdependent mono-ribosyl ATPase (sirtuins), HATs (acetylase) and DNA methylase and DMTs (demethylase) $[4,5]$. On the other hand, nutrients can indirectly stimulate the expression of transcriptional complexes or modulate the expression of gene coding for regulatory microRNAs.
The aim of the present review is to compare results regarding the effects of some nutrients, especially those present in Mediterranean foods, on osteoblast and adipocyte cells originated from mesenchymal stem cells.

\section{Carbohydrates}

Diet carbohydrates are the broadly used nutrients for humans, and their utilization supplies the main energetic source for cells. Moreover, cells utilize carbohydrates also to build many polymers present into tissues, such as glycans. The main carbohydrate utilized by cells is glucose, which enters across specific and regulated transporters, it can be utilized to produce ATP and to synthesize structural molecules. Glucosamine (GlcN) a glucose-derivative, broadly present in living world is utilized to build glycosaminoglycans, the main components of extracellular matrix (ECM) of connective tissues. For instance, $\mathrm{GlcN}$, as $\mathrm{N}$-acetyl glucosamine (GlcNAc), is present in Hyaluronic acid and as N-acetyl glucosamine 6-sulfate (GlcNAc6S) in Keratan sulfate, two glycosaminoglycans that are present in cartilage. For this reason, since several years, GlcN has been orally administered to osteoarthritic (OA) patients, whose articular cartilage is deeply

"Corresponding Author: Dr. Anna Scotto d'Abusco, Department of Biochemical Sciences, Sapienza University of Roma, P.le A. Moro 5, 00185 Roma, Italy; Tel: +39 06 49910939; Fax+39 05 440062; E-mail: anna.scottodabusco@uniroma1.it

Citation: Scotto d'Abusco A, Ammendola S, Cocchiola R, Lopreiato M (2018) Nutritional Screening Tools for Hospitalized Children. Int J Clin Nutr Diet 4: 131. doi: https://doi.org/10.15344/2456-8171/2018/131

Copyright: (C) 2018 Scotto d'Abusco et al. This is an open-access article distributed under the terms of the Creative Commons Attribution License, which permits unrestricted use, distribution, and reproduction in any medium, provided the original author and source are credited. 
Citation: Scotto d'Abusco A, Ammendola S, Cocchiola R, Lopreiato M (2018) Nutritional Screening Tools for Hospitalized Children. Int J Clin Nutr Diet 4: 131. doi: https://doi.org/10.15344/2456-8171/2018/131

damaged. Several clinical trials have been conducted to evaluate the effectiveness of oral administered GlcN, [6-8] and several in vitro studies, using cartilage cells, chondrocytes, have also been conducted with the aim to elucidate the mechanism of action of GlcN [9-11], obtaining inconsistent outcomes. A recent review analyzed all published manuscript regarding both clinical trials and in vitro studies, highlighting that $\mathrm{GlcN}$ has many potential mechanisms of action on articular structures and concluding that the inconsistent outcomes, found in different studies, could be due to different formulations, quality of clinical trials and publication bias [12]. In our laboratory, we analyzed the anabolic effects of GlcN and an its $\mathrm{N}$-acetyl phenylalanine derivative (NAPA) [13] in rabbit and mouse OA models, finding very encouraging results $[14,15]$. In rabbit OA model we induced osteoarthritis injecting Vitamin A in rabbit joint and then we injected GlcN or NAPA, finding that the joints treated with the two molecules showed a healthy morphology compared

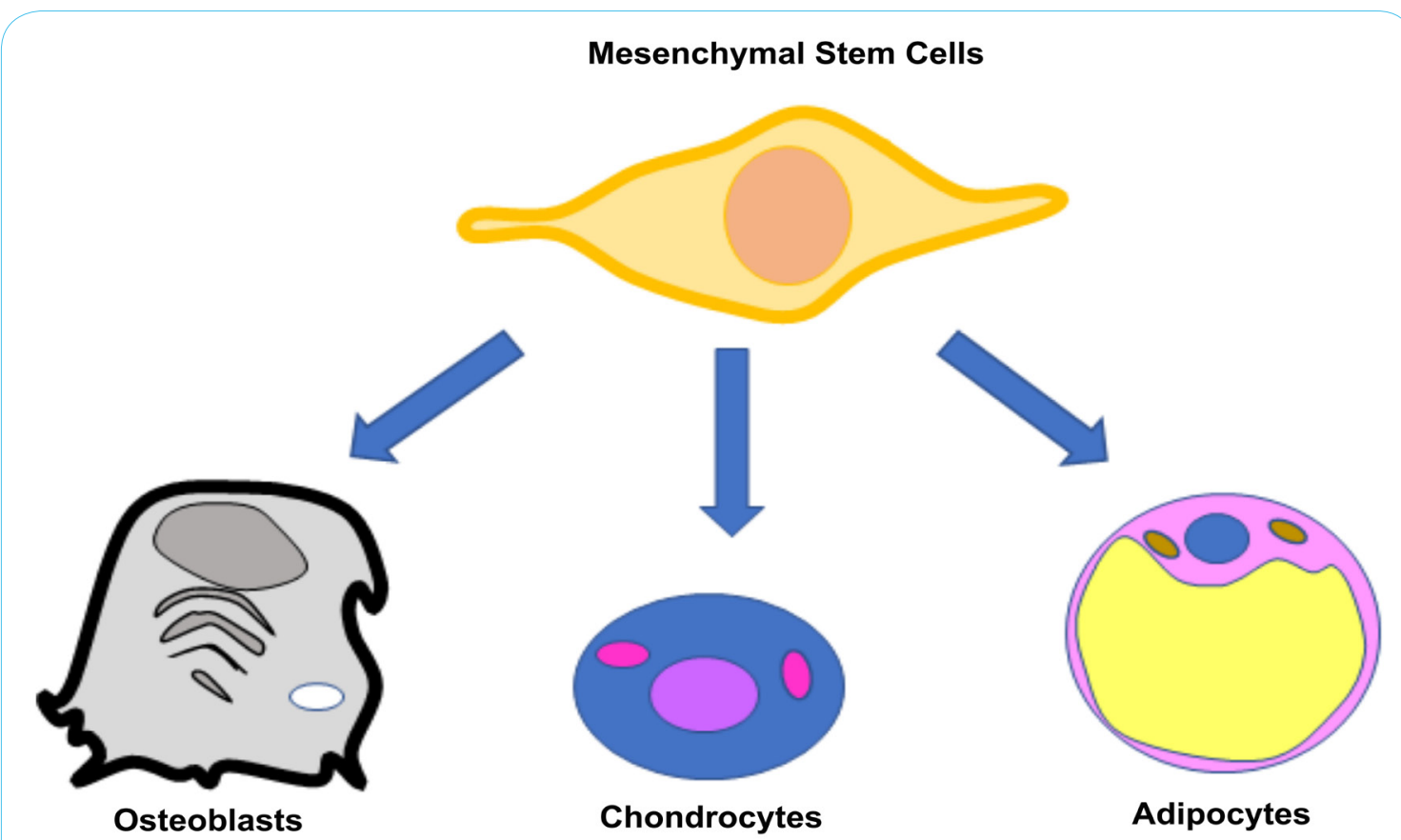

Figure 1: Mesenchymal Stem cells differentiation. Cells can be cultured in vitro to generate osteoblasts, chondrocytes or adipocytes. The end-stage cell type is dependent on the culture conditions, media, and supplements.

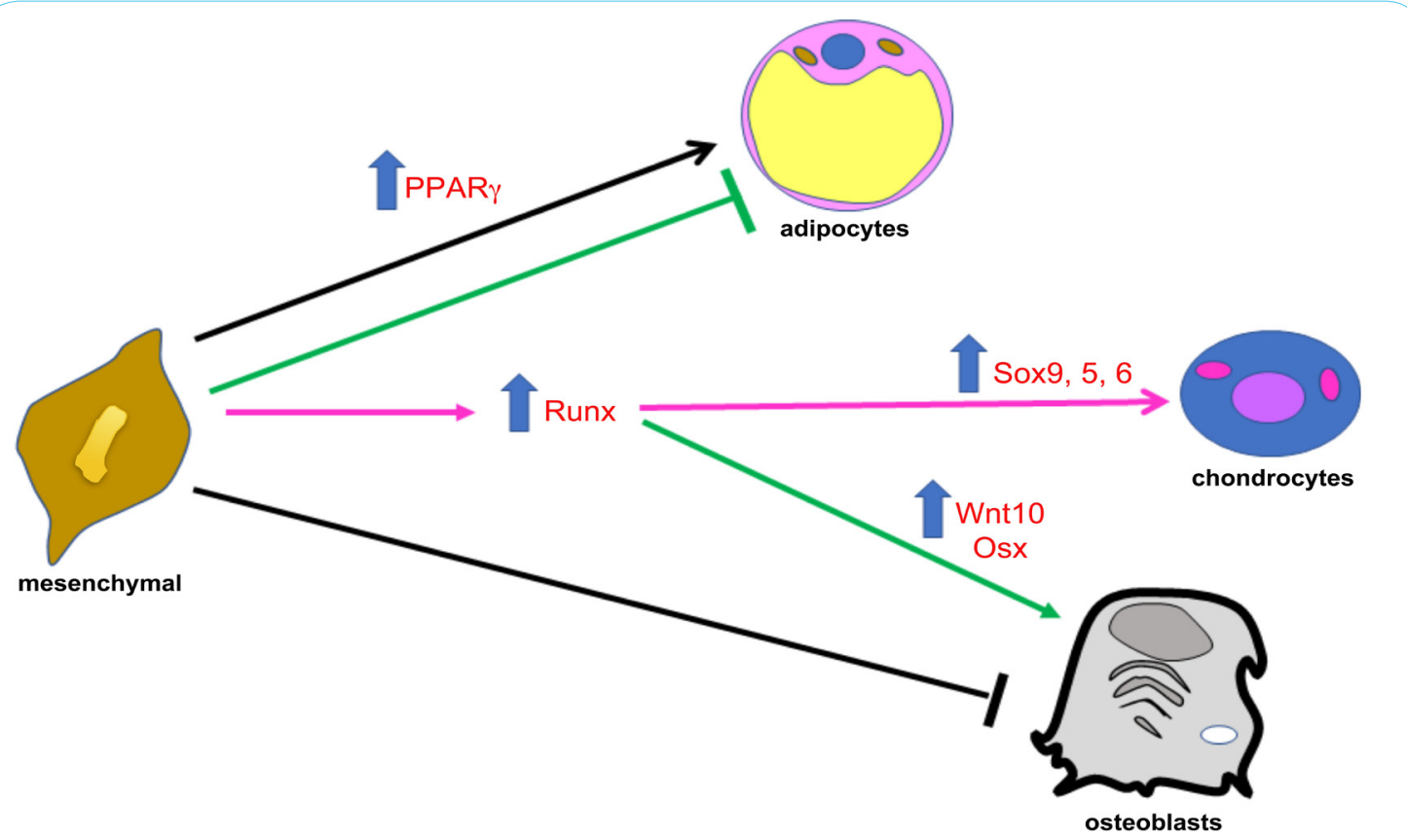

Figure 2: A schematic model for the differentiation of mesenchymal stem cells into tissue-specific cells by specific transcriptional factors. Mesenchymal stem cells can differentiate into osteoblasts, chondrocytes, and adipocytes. Each differentiation program is regulated by specific transcription factors: Runx2/Osterix (pink and green arrows, respectively), Sox5/6/9 (pink arrow), MyoD family (green arrow), and PPAR $\gamma$ (black arrows), respectively. 
to joints treated only with Vitamin A [14]. In mouse OA model, the osteoarthritis was surgically induced using destabilization of the medial meniscus (DMM), which is considered more suitable to mimic OA, finding that the intra articular administration of NAPA markedly improved the physical structure of damaged cartilage [15]. We also studied the effects of GlcN and NAPA in vitro, using both chondrocyte cell line and human primary chondrocytes, finding that GlcN and NAPA have a good anti-inflammatory activity, in particular they were able to interfere with AP-1 pathway by inhibiting p38 and JNK kinases and consequently MMP-1, -3 and -13 syntheses $[16,17]$. Next, we found that both GlcN and NAPA were able to inhibit NF$\kappa B$ pathway, preventing the migration into the nucleus of IKKa, one of the components of IKK complex, which controls the activation of NF-kB [18]. Moreover, we studied the effects of GlcN and NAPA on synthesis of ECM components, such as collagen type II, hyaluronic acid and proteoglycans, finding that at different extent, the two molecules showed a good effectiveness [19]. These findings, together with results obtained by other authors, suggest that glucosamine and its derivatives could be able to treat patients with OA, especially if intra-articularly injected.

The effects of GlcN have been studied also in osteosarcoma cell lines [20]; osteosarcoma is the most common primary bone cancer in childhood and adolescence and is due to the cancer progression of the bone cells, osteoblasts. In our laboratory, we studied the effects of another glucosamine derivative, NCPA, on osteosarcoma cell lines, 143B and Saos-2; 143B cell line represents a good in vitro model to study osteosarcoma, due to its ability to migrate, to grow independently of the anchorage and for the poor cell adhesion activities [21], whereas, Saos-2 cell line is considered a good model to study human osteoblasts [22]. We found that NCPA was able to inhibit IKKa nuclear translocation, and consequently to stimulate Maspin production, a class II tumor suppressor molecule, whose expression is controlled by nuclear IKKa. Moreover, we found the decrease of $\beta 1$ Integrin expression, the down-regulation of metalloproteases MMP-9 and MMP-13 production and cell migration inhibition. Taking into account that $\beta 1$ Integrin and MMP-9 and -13 have been correlated with the invasiveness of osteosarcoma, NCPA seemed able to counteract the invasiveness of $143 \mathrm{~B}$ cell line affecting the osteosarcoma metastatic ability [23].

The effect of glucosamine on adipocytes has been studied in 3T3L1 adipocytes using the phosphorylated molecule, glucosamine-6phosphate $(\mathrm{P} 6 \mathrm{GlcN})$. The outcomes showed that $\mathrm{P} 6 \mathrm{GlcN}$ inhibited the lipid accumulation in cultured cells during adipocytes differentiation and induced the decrease of Peroxisome Proliferator-Activated Receptor $\gamma(\operatorname{PPAR} \gamma)$, sterol regulatory element binding protein 1 and CCAAT/enhancer binding protein- $\alpha$ in dose dependent manner [24].

Moreover, the treatment with $\mathrm{P} 6 \mathrm{GlcN}$ induced the up-regulation of pre-adipocyte factor 1 and down-regulation of adipocyte specific genes. Considering that adipocytes, osteoblasts and chondrocytes come from mesenchymal stem cells, could be hypothesized that the treatment with $\mathrm{P} 6 \mathrm{GlcN}$ could induce a differentiation of preadipocyte cells toward bone cells, which would be very interesting in pathology as osteoarthritis in which chondrocytes and osteoblasts dedifferentiate.

\section{Fibers and complex carbohydrates}

Fibers and resistant starches are indigestible complex carbohydrates, which constitute a large part of foods and are considered important also for their indirect activity on microbiota. These molecules can promote proliferation of intestinal microorganisms and probiotics, which ferment not-digested dietary fibers. Fiber fermentation may yield short chain fatty acids which target Fatty Acid Receptors present also on mesenchymal stem cells surface. Fibers can stimulate cell differentiation and growth through modulation of PPAR receptors that are generally up-regulated in osteoblasts and down-regulated in adipocytes.

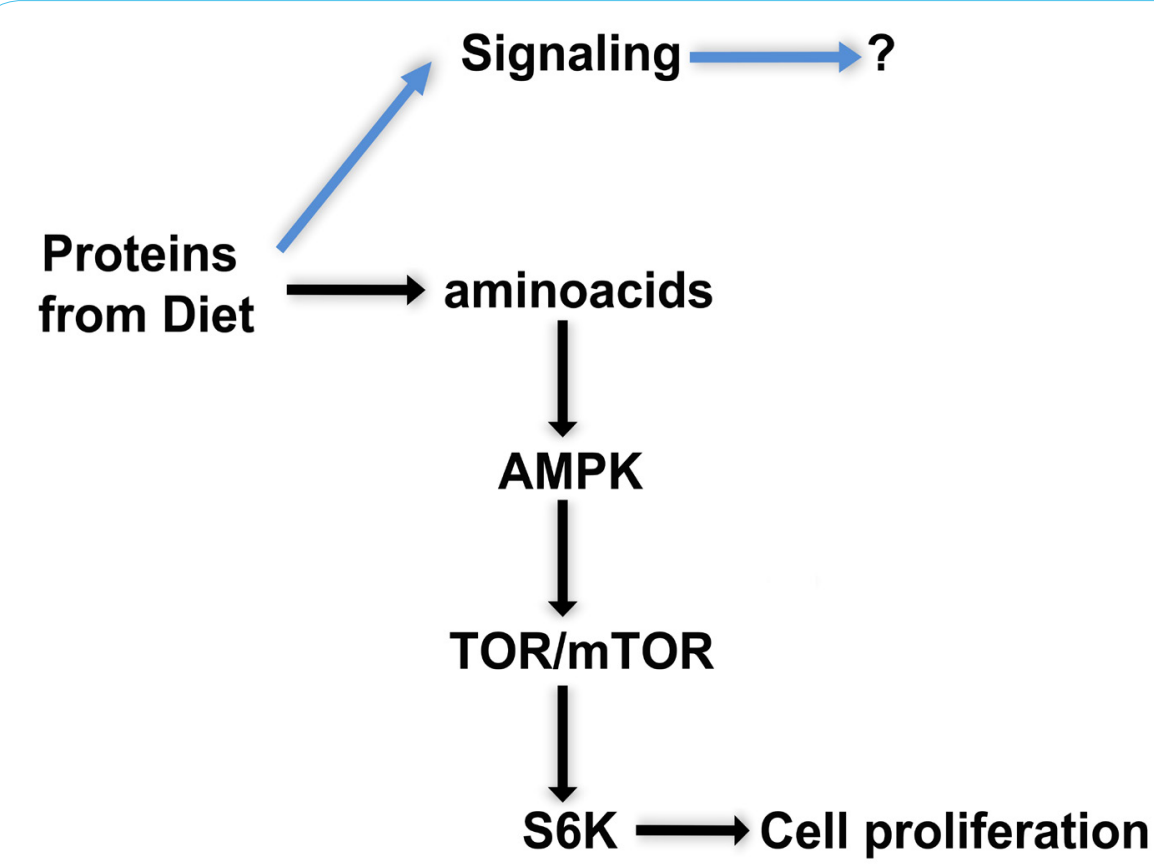

Figure 3: A schematic model of the effect of diet protein uptake on cell growth and differentiation. Protein intake stimulates mTOR-mediated activation of p70 S6K and induces differentiation of Pluripotent Stem Cells. 


\section{Proteins/Amino acids}

Beside the nutritional value of protein foods, there are differences among meat, fish and vegetable proteins. Associated to proteins several types of compounds can be found, depending on sources they are from: in animal tissues are present cholesterols, whereas in vegetables phytosterols. Moreover, protein-link cofactors, prosthetic groups and micronutrients, which are released after the proteolysis. Following digestion processes, oligopeptides reach small intestine where they are digested to amino acids, assimilated by enterocytes are delivered to liver. Amino acids and linked molecules affect physiology of liver and muscle and consequently bone (Figure 3). Protein source is relevant also for the metabolic effects on mesenchymal cells. Whey and soy proteins have been described to be effective on bone and adipose cells. Whey proteins (WPs) are obtained as product of dairy processing and they are quite heterogeneous: isolated WPs, purified WPs and hydrolyzed WPs. In our experience, each WP shows different biological effects, likely due to their contents in some proteins, such casein and lactoferrin.

Dietary intake of proteins is useful for the growth or maintenance of muscle mass and for the growth, development and maintenance of bone. Previously, we studied the effects of a nutraceutical composition based on whey proteins on Saos-2 osteoblast cells, finding that whey proteins in association with L-carnitine, carnosine and arginine ketoglutarate, were able to induce the over-expression of the gene coding for MyoD_1 transcription factor and down-regulate the expression of cytoplasmic isoform of Creatine Phosphokinase (CPK) gene expression, moreover they slightly increase adenosine triphosphate (ATP) amount and decrease LDH activity [25]. MyoD_1 controls its own expression and those of other genes, including CPK genes [26] and is involved in several pathways, among them the osteogenic differentiation. CPK is an enzyme required for cell energy homeostasis and intracellular exchange of ATP. Regulation of CPK gene expression is considered important for differentiation of mesenchymal cells in muscle and osteoblast cells. On the other hand, the increase of CPK level in serum of patients, who are treated with some pharmacological therapy, such as statins, is considered a negative side effect of that therapy. The administration of our nutraceutical composition to patients under statin treatment and complaining myalgia, resulted in amelioration of those symptoms. Moreover, clinical analyses revealed that the CPK serum level was considerably decreased [25].

Recently, whey protein isolates have been shown to have positive effects on growth of Saos-2 cells and neonatal fibroblast and not on adipose-tissue derived stem cells [27]. Moreover, the whey proteins increased the expression of osteogenic markers, as Collagen type I and Alkaline phosphatase, both in adipose-tissue derived stem cells and in Saos-2 cells and stimulate the latter to deposit calcium also in non-osteogenic medium [27]. These results are very interesting, considering that whey proteins can induce osteogenic differentiation in osteogenic-like cells and in stem cells derived from adipose tissue.

Excess of adipose tissue and sarcopenia can be cause of morbidity and mortality in obese elderly population. It has been shown that the administration of whey proteins and essential amino acids to these people preserves lean tissue [28]. Moreover, the provision of essential amino acids, during caloric restriction-induced weight loss, promotes the preferential reduction of adipose tissue, whereas the lean tissue is preserved [28].
The activity of amino acids derived from hydrolysis of dietary proteins, is mostly mediated by the mTOR system, which is a sensor of energy intake able to regulate cell growth through the autophagocytosis process. Although mTOR is the catalytic center of the two signaling complexes mTORC1 and mTORC2 involved in regulation of skeletal muscle protein synthesis, a recent observation proposed a novel role for mTORC1 and $\mathrm{mTORC} 2$ in the regulation of the white-brown phenotypic switch of adipocytes. Interestingly, mTORC1 has been observed promoting the osteoblast differentiation in a BMP2 dependent way [29].

\section{Lipids}

Lipids from diet are high energetic and structural molecules, whose uptake in enterocyte cells is mediated by NPC1L1 receptors and other receptors or lipid transporters [30]. Inside enterocytes, dietary fats are esterified before to assembly circulating chylomicrons, which are sent to adipocytes and hepatocytes. In hepatocyte lipids are stored or metabolized to produce energy or made available for other tissues. It has been shown a strict relationship among serum lipid profile, bone and adipose tissues, for instance, a positive correlation has been found between HDL and femoral neck mineral density, and a negative association between HDL and osteocalcin in male subject with spinal cord injury [31]. Moreover, bone cells have been shown to utilize lipid metabolism, while previously it was assumed that bone cells utilized mainly glucose metabolism [32]. Lipids, due to their lipophilic nature, can across the cell membrane and enter inside cytoplasm and nucleus where their activity is fine tuned by several mechanisms, which are controlled by the PPAR receptors in response to energy requirement. In osteoblast cells several factors are involved in cell growth and differentiation regulated by PPAR factors. In adipocytes the PPAR receptors have a cross-talk with insulin dependent fat accumulation, whereas in osteoblasts PPAR receptors respond directly to mTOR signaling [33].

Both osteoporosis and excess of central obesity, a biomarker of insulin resistance, are controlled by osteocalcin and leptin, produced by osteoblast and adipocytes, respectively. These proteins have significant effects on energy homeostasis and on skeleton and it is now clear that bone and adipose tissues share common regulatory pathways. During starvation, as malnutrition or anorexia nervosa, the bone formation is reduced [34,35]. The link between these two occurrences is unclear, but it is likely that changes in circulating hormone levels is involved. The adipocyte-derived hormone leptin has been shown to modulate bone metabolism [36], nevertheless, conflicting data are reported, ranging from net bone formation to detrimental effects on bone formation $[37,38]$. The administration of leptin to mice exposed to starvation up-regulates bone turnover [39], whereas the administration of leptin to human subjects, who underwent to weight loss, doesn't prevent the bone mineral metabolism changes [40]. Likely, the discrepancy is due to different models used, and further studies are needed especially in humans, to settle the matter. However, obese individuals produce normal level of leptin, but often they are leptin-resistant. Leptin has been shown do not influence proliferation of bone marrow stromal cell line, nevertheless it increases some biomarkers for bone turnover, such as osteocalcin (OC) [37]. On the other hand, OC has been shown to regulate lipid and glucose metabolism, for instance OC can stimulate cyclin D1 and insulin in pancreatic beta-cells and adiponectin, an insulin-sensitizing adipokine, in adipocytes [41]. 


\section{Liposoluble vitamins}

All vitamins, with the exception of vitamin $\mathrm{D}$, which is endogenously synthesized, must be supplied by diet, even if, vitamin D intake from foods is needed especially for people scarcely exposed to sun or with vitamin D receptors deficiency, renal and liver failures. Vitamin D has been grouped among secosteroid with several roles including its relationship to mTOR system.

Vitamin D and its metabolizable precursors are present at effective amount only in fish, liver and some mushrooms. The intestinal absorption of this vitamin is controlled by serum calcium and hormone levels and it exhibits a hormone-like behavior. The ability to protect bone is well known, for instance it induces transcriptional networks during osteoblast differentiation and bone formation [42]. Moreover, adipocytes convert $25(\mathrm{OH}) \mathrm{D} 3$ to $1,25(\mathrm{OH}) 2 \mathrm{D} 3$ controls their cellular expansion. On the other hands the Vitamin D receptor (VDR) is expressed in human adipocytes which expansion seems to be facilitated by the vitamin $\mathrm{D}$ and macrophages activation [43].

Vitamin $K$ is present in the diet in form of phylloquinone and menaquinones. Phylloquinone, is present in high amount in leafy plants and represents the best characterized vitamin $\mathrm{K}$ form in terms of food composition and dietary intakes. This vitamin is required for the coagulation and it has also been shown to promote tissue calcification via Gamma-glutamyl carboxylase calcium-dependent enzymes [44]. Remarkable, vitamin D and vitamin $\mathrm{K}$ are able to form complex with vitamin $\mathrm{D}$ receptors in PPAR signaling.

Vitamin $E$ inhibits differentiation of osteoblasts especially from early stage to osteoid-producing stage as shown by increase of ALP expression in a dose-dependent manner [45].

In adipocytes the role played by Vitamin $\mathrm{E}$ is important for adipogenesis since ROS species increase during obesity, thus the antioxidant properties of vitamin E contribute to inhibit adipocytes expansion [46].

Retinoids derive from several Mediterranean foods and they are delivered also to adipocytes. Retinyl-ester and $\beta$-carotene, postprandially present in chylomicrons, reach adipose tissue. Lipoprotein lipase present on endothelial cells facilitates the uptake of these postprandial retinoids into adipose tissue.

The presence of $\beta$-carotene monooxygenase type $1(\mathrm{Bcmol})$ in adipose tissue enables the conversion of $\beta$-carotene to retinaldehyde.

Recently, vitamin E has been shown to promote both beige adipocyte differentiation in 3T3-L1 cells and rat white adipose tissue mediated by PPAR regulation. Contrary, no relevant activity has been reported on osteoblasts.

Vitamin $A$ is a negative regulator of bone mineralization and has been associated with increased risk of fractures in humans, likely due to the decrease of the expression of osteocalcin by acting on Runx 2 and Osterix [47].

On the other hand, retinoic acid differentially regulates several genes also in adipose derived stem cells through the WT1 factor, a zinc finger transcription factor involved in cell growth control, showing that Vitamin A can promote adipose expansion especially at level of visceral fat [48]. participating to metabolism of vitamin $\mathrm{D}$ and in turn the vitamin

A vitamin $\mathrm{K} 2$ analog, Ubidecarenone, involved in mitochondrial electron transport, has been found to promote osteoblast differentiation. Q10 is a coenzyme of several enzymes and is found in several dietary foods, it up-regulates the expression of several biomarkers of osteoblastogenesis [49]. Coenzyme Q10 has been shown able to significantly reduce the white adipocytes content and increase the function of brown adipocytes, via the CaMKII-MEK1/2ERK1/2 signaling pathway, thereby increasing intracellular cAMP. The increased level of cAMP in turn activates AMPK and inhibits the expansion of adipose tissue [50].

\section{Free fatty acids}

Dietary Free fatty acids (FFAs) are differently associated to osteogenesis/adipogenesis cell differentation and growth. In dietinduced obese mouse, FFAs have been shown to be active on mouse bone marrow-derived mesenchymal stem cells (BMSCs), promoting osteoblast growth and suppressing adipogenic differentiation [51]. An important source of Short Chain Fatty Acids (SCFAs) are the saccharolytic microbiota able to ferment dietary fibers. In the last years, it has been elucidated that the biological effects of SCFAs are mediate by G-coupled protein receptors (GPRs), present on cell membrane surface of several tissues [52]. GPR43 and GPR41 are abundant fatty acid receptors in adipose tissue, especially white tissue, where they can decrease lipolysis and insulin-dependent fat accumulation and in osteoblasts, where they can increase bone density [53].

In this section we aim to shed light on the physiological roles and development of drugs targeting these receptors. On the other hand, knowledge of the effects of fatty acids on mesenchymal cells is useful to design a suitable chemical-defined media for their differentiation and maintenance.

\section{Long fatty acids}

All foods are rich in organic acids, although they are also produced by cell metabolism. The organic acids are characterized by an hydroxylic group and the chain size, the branches and the hydrogen oxidation can affect their biological activities. The chemical features are relevant for the activity of the Functional Long Fatty Acids (FLFAs), which are active on mesenchymal stem cells (MSCs) as shown for osteoblasts [54]. The $\omega-3$ series such as linolenic (ALA), eicosapentaenoic (EPA), docosahexaenoic (DHA) and the $\omega-6$ series linoleic (LA), $\gamma$-linolenic (GLA), arachidonic (ARA) acids show different biological effects on MSCs. ARA has been shown to induce adipogenesis in human MSC cultures, and at high concentration inhibits osteoblastogenesis. In MSC, $\omega$-6-arachidonic PUFA promotes the differentiation of adipocytes and inhibits the osteoblast differentiation. While $\omega-3$ series do not affect the adipogenic differentiation and their effects on osteoblastogenesis are less relevant [55]. Dietary uptake of $\alpha$-linoleic acid is essential to synthesize the $\omega-6$ series; its amount decreases alongside with the increase of the level of dietary a-linoleic acid and viceversa. Interestingly, conjugated linoleic acid isomers inhibit adipogenesis and promote bone mass formation [56,57].

OMS reported that optimal $\omega-3 / \omega-6$ ratio is determinant for the biological activity of PUFAs and an increased ratio prevents bone mass loss.

In the last decades an increasing number of studies showed that the effects of Fatty Acids on adipocytes and osteoblasts are mediated by the PPAR $\gamma$ pathway [58] (Figure 4).

Int J Clin Nutr Diet

ISSN: 2456-8171

IJCND, an open access journal Volume 4. 2018. 131 
Adipocytes contain high amount of saturated and mono-unsaturated FFAs, including palmitic, stearic and oleic acids; polyunsaturated FFAs (PUFAs), such as linoleic acid. Contrary arachidonic and linolenic acid are present at low amount. Interestingly adult bone marrow mesenchymal stem cells (BMSCs), whose can differentiate in adipocytes, have been found to contain high amount of palmitic and oleic acids. A BMSC cell culture showed that the composition of FFAs in BMSC-derived adipocytes was altered compared with adult adipocytes and essential FFAs, that may directly affect signaling related to their lipolysis/lipogenesis functions, were lacked [59].

A recent study shows that a reduction of saturated fatty acid oxidation can decrease human BMSC proliferation and cause cell death, suggesting that saturated fatty acids may be involved in the long-term impairment of BMSC survival in vivo [60].

\section{Short fatty acids}

Differently from long molecules, small chain Fatty acids (SCFAs) are end-products of bacterial fermentation and they can be found in fermented foods. Otherwise some SCFAs are produced by fermentations of dietary fibers. Small Fatty acids are aliphatic molecules travelling through blood flux and binding G-coupled Receptors of several tissues, including white adipocytes and osteoclasts (Figure 5). Recently, propionate and butyrate have been found to bind GPR40 in osteoclasts down-regulating essential osteoclast genes such as TRAF6 and NFATc1 [54]. A study on adipogenic differentiation of human chorion-derived mesenchymal stem cells, showed that propionate inhibits the formation of adipocytes from MSCs and acts on adipogenesis predominantly via GPR43 [61].

\section{Lipids from Diet

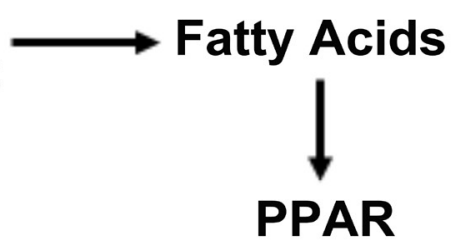

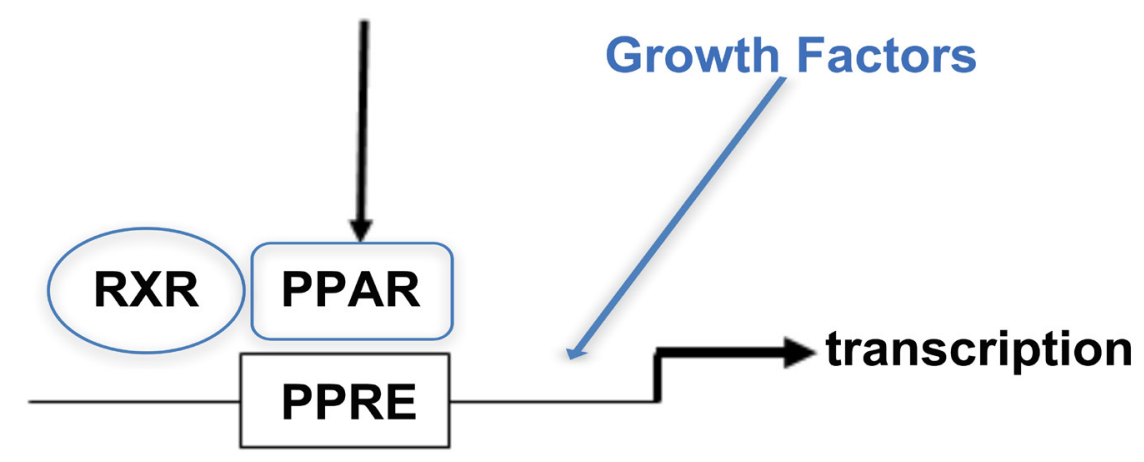

Figure 4: A scheme of dietary regulation of cell growth and differentiation by lipids uptake. Fatty Acids going through cytoplasmic membrane, can migrate in cell nucleus and bind PPAR receptors. This mechanism increases the synthesis of cell growth factors.

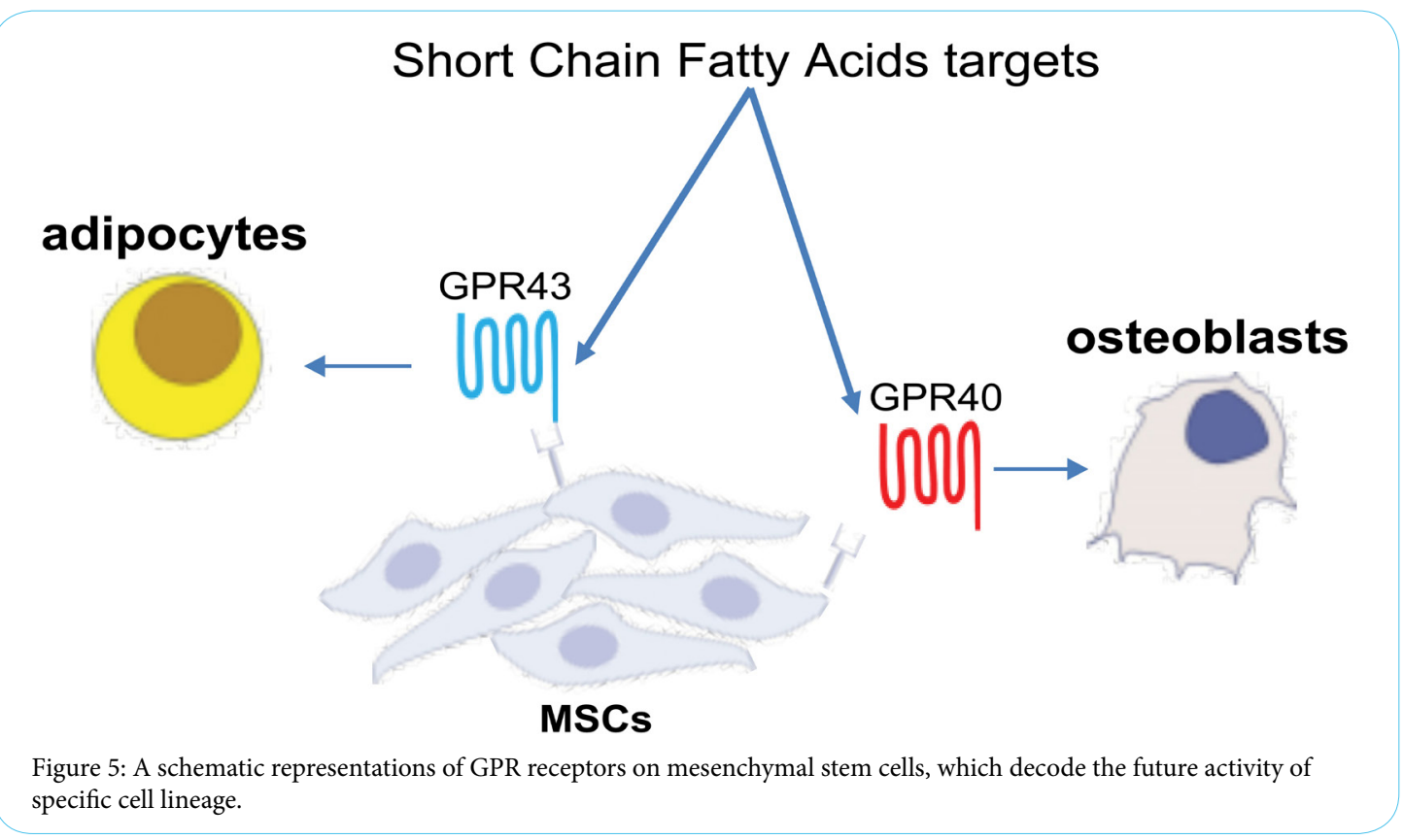


The tissue specific expression of Free Fatty Acid Receptors such as GPR40 and GPR43 on bone and adipocyte cells, could account for some observed differences among biological effects of SCFA. For example, butyrate inhibits adipocyte differentiation, but it may induce osteogenic differentiation from mouse adipose-derived mesenchymal stromal cells [62]. FFAs act on adipocytes and bone, via several mechanisms depending by the inhibitory (Gi) or stimulatory (Gs) effects of the associated $\mathrm{G}$ protein.

\section{Other acids}

Several carboxylic acids and their derivatives can be found in foods since they are secondary metabolites of vegetables and in meat often where they enhance flavour. Several organic acids are phenolic acids well studied for their scavenger activity on free radicals. Gallic, ellagic, p-coumaric, caffeic, and ferulic acids show activity on the mesenchymal stem cells. Compounds, such as hydroxytyrosol, luteolin, apigenin increase osteoblast proliferation [63]. Rosmarinic acid has been found to protect mesenchymal cells by oxidative stress [64].

The Ellagic acid, present in several sources as chestnut, pomegranate, some edible berries, and other plants with high content of hydrolyzable tannins, has been showed in adipocyte rat model to reduce adipogenesis acting on $\mathrm{Rb}$ phosphorylation [65]. Ellagic acid on osteoblasts in vitro stimulates osteoblast differentiation [66] or has been showed useful for bone formation [67].

Other molecules, such as maslinic acid, widely present in dietary plants and especially in olive fruit skins and hawthorn, exhibit several nutraceutical features described also in osteoclastogenesis [68] and on 3T3-L1 adipocytes in which maslinic acid has an antiadipogenic effect [69].

Vitamin C or L-ascorbic acid at physiological level is transported into osteoblasts through SVCT1 and SVCT2 transporters and in an in vitro study showed that the ascorbic acid influences cell proliferation and stimulates procollagen type I hydroxylation [70,71]. Recently, SVCT2 transporter has been shown to play a vital role in the mechanism of BMSC survival under stress conditions, such as oxidative stress.
In adipocytes a mechanism involving PPAR $\gamma$ has been proposed to explain this observation. On adipocytes the ascorbic acid promotes the proliferation of human adipose-derived stem cells via p53-p21 pathway [72]. In a mouse model of tendonitis, ascorbic acid increases the viability of transplanted pre-adipocytes [73].

Interestingly vitamin $\mathrm{C}$ deficiency accelerates bone loss inducing an increase in PPAR $\gamma$ expression in SMP30 knockout mice [74].

\section{Probiotics}

Microorganisms able to survive through gastrointestinal tract and to colonize distal tracts promoting people health are considered probiotics. The immunomodulation of gut-associated lymphoid tissue (GALT), the control of eubiosis and production of vitamins are considered healthful effects of probiotics. Some probiotics must compete with resident microbiota, and both may produce short chain fatty acids (SCFAs). SCFAs received increasingly interest for their energetic and functional roles played in nutrition. These molecules are mostly produced by the microbiota as consequence of fiber fermentation and their levels can be increased by probiotic uptake. Probiotics may offer a therapy to treat gastrointestinal diseases and other pathologies such as obesity. Recently the role of probiotics on health received an increasing interest since they produce Short Chain Fatty Acids by fermentation of some foods. Acetic acid, propionic acid and butyric acid targeting GPR41, GPR43 receptors on adipocytes inhibit lipolysis and insulin dependent fat accumulation. Mainly probiotics belong to lactobacilli and streptococcus genus and are mostly present in dairy foods and some beverages and recently also other genus are under evaluation. More reports describe the efficient effect of lactobacilli to control obesity [75,76,77]. Lactobacillus rhamnosus GG seems to alleviate adipogenesis by inhibiting triacylglycerol accumulation [78]. Lactobacillus plantarum strain $\mathrm{N}^{\circ}$ 14 has been found to reduce adipocyte size [79]. Recently specific Lactic acid producers, have been shown modulate the adipokines profile [80].

Some probiotics, such as Lactobacillus helveticus, have been shown to be indirectly active on osteoblasts. This microorganism, by milk fermentation, produces small peptides such as isoleucyl-prolyl-proline
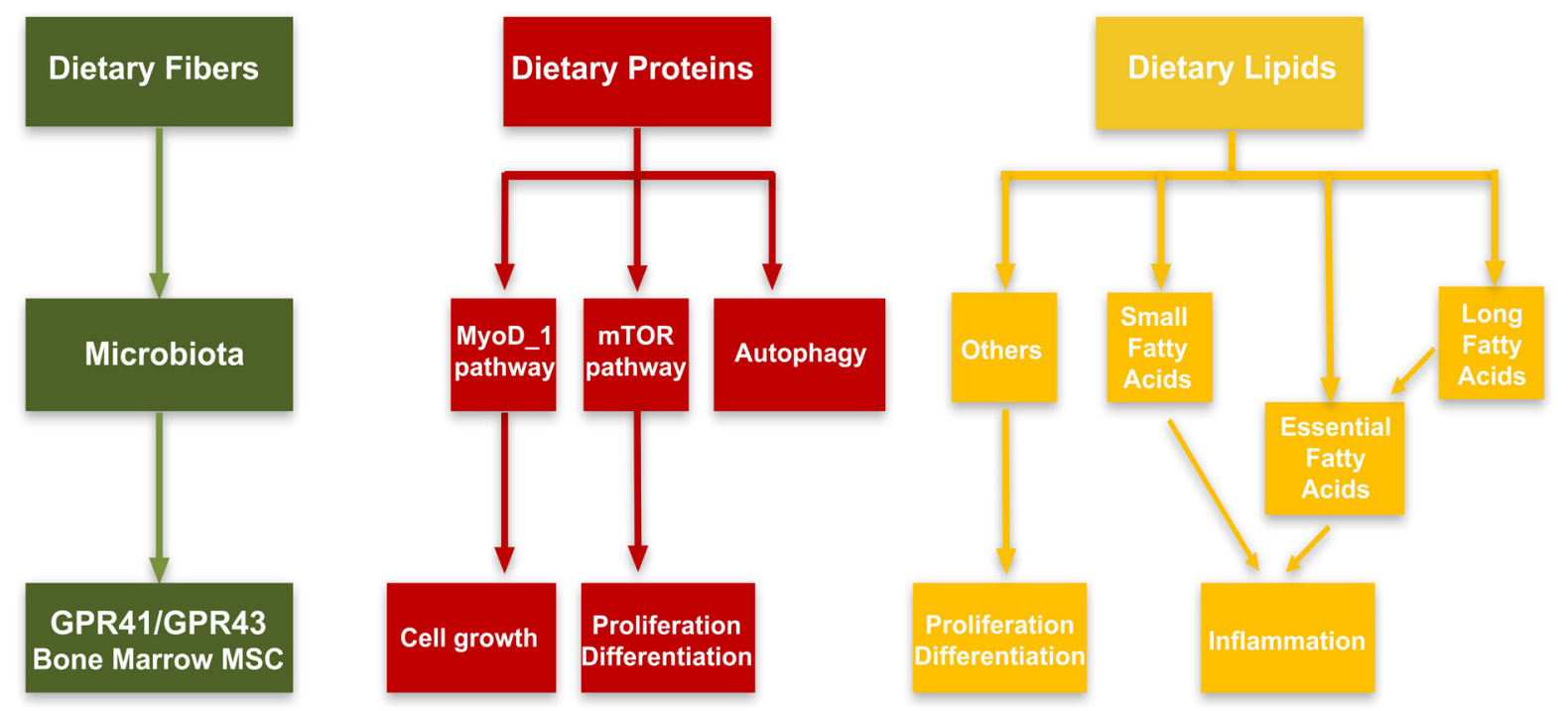

Figure 6: A schematic flow-chart from foods to cell differentiation or growth. 
(IPP) and valyl-prolyl-proline (VPP) which in vitro promote osteoblast activation [81]. Recently also Bifidobacterium bifidum MF $20 / 5$ has been found to produce small peptides active on osteoblasts [82]. Probiotics have been proposed for treatment of osteoporosis [83].

\section{Secondary metabolites from plant and herbal sources}

\section{Polyphenols}

Polyphenols are a broad class of compounds widely represented in fruits, vegetables and beverages and have been carefully studied for their antioxidant effects. These compounds exhibit a dose dependent activity: at high dose, they form multimers due to intramolecular hydrogen bonds or ion pairs. Polyphenols can act through membrane receptors as well as nuclear receptors [84]. Epigallocatechin 3-gallate exhibits an anti-senescence effect in human Mesenchymal Stem Cells [85]. Some polyphenols modulating the gene expression promote cell differentiation [86]

We have studied the effects of Olea europea fruit blending on Saos2 osteoblast cell line finding that different blends modulate lipidsensing nuclear receptor PPAR $\gamma$, cell survival and oxidative stress response [87]. On the Saos-2 we also showed the modulatory effect of flavonoids from citrus fruits, which was able to down-regulate some pro-inflammatory genes or to up-regulate some metalloproteases [88]. However, phenol acids from olive oil such as luteolin, apigenin and other molecules were found to stimulate osteoblastic proliferation [89].

Soy isoflavones have been found useful to treat postmenopausal osteopenia, they show an estrogen-like activity that in vitro was showed to synergize with vitamin D3 increasing cell proliferation of pre-osteoblast [90].

Recently epicatechin and luteolin-7-O- $\beta$-D-glucoside have been shown to protect the mesenchymal stem cells from oxidative stress [91].

\section{Sulfoorganic compounds}

Sulfoorganic compounds are involved in the control of gene expression, since some molecules show inhibitor activity of enzymes involved in chromatin remodeling such as HADCs and HAT. These enzymes can hyperacetylated histones proteins. Similar sulfoorganic compounds affect DMT enzymes, influencing expression of genes coding for molecules acting on DNA methylation. Typical compounds are sulforaphane glucosinolates from broccoli, which control oncogenes.

Sulforaphane is an isothiocyanate, which, in osteoblastic M3T3-E1, has been shown protective activity against drug-induced apoptosis. Sulforaphane exhibited its antioxidant activity through induction of nuclear factor erythroid 2-related factor 2 (Nrf-2) and activation of the Nrf2/antioxidant response element pathway [92].

Sulforaphane inhibits adipogenesis and activates the AMPK pathway in obese mice. In particular 1-isothiocyanate-4-methylsulfonyl butane has been shown able to promote glucose and lipid utilization in 3T3-L1 mature adipocytes through the up-regulation of nuclear factor E2-related factor 2/sirtuin 1/peroxisome proliferator activated receptor gamma coactivator 1 alpha signaling [93].
Allicin from garlic is another sulfo-compound able to regulate CREB/ERK signaling in osteoblast by decreasing oxidative stress in osteoblast. Free radicals have been found to promote osteoporosis by stimulating apoptosis of osteoblast. Allicin has been shown to counteract the oxidative stress-induced apoptosis stimulating scavenging enzymes [94].

Allicin seems healthful also for adipocytes since upregulates the uncoupling protein and activates AMP protein kinase (AMPK) contributing to reduce body weight of obese mouse [95].

Recently it has been shown that a diet with black garlic, a fermented fresh garlic, exhibits several bioactivities, but the contamination with SCFAs from fermentative process cannot be excluded [96].

\section{Carotenoids}

Carotenoids are present in several herbs, plants and seafoods, these molecules exhibit several biological activities such as inhibition of adipocyte differentiation acting on the PPAR signaling and the retinoic acid receptors. There are not significant report providing relationships among carotenoids and mTOR signaling.

Among carotenoids from vegetable it is interesting the finding that Lycopene protects BMMSCs against ischemia-induced apoptosis in vitro. Lycopene increased osteoblast proliferation, via a decrease on apoptosis, and differentiation. The observed effects appear to be related to NF- $\kappa \mathrm{B}$ signaling, and lycopene appears to promote an anabolic state of bone metabolism, stimulating osteoblastogenesis and inhibiting osteoclastogenesis [97].

Lutein, a vegetable xanthophyll, suppresses IL-1 induced osteoclast differentiation but on cultured osteoblast upregulates the expression of the BMP-2 inducing the bone mineralization [98]. In human cultured adipocytes, lutein stimulated the secretion of the Factor D, also known as adipsin, a serin protease which stimulates transport of glucose for triglyceride accumulation since inhibits lipolysis [99]. This result shows that in adipocytes inhibition of lipolysis can be mediated by several factors.

\section{Conclusion}

Diet and life style are involved in pathological mechanisms affecting adipocytes and osteoblasts, such as obesity, diabetes and insulin resistance syndrome. Energy intake influences the mechanisms controlled by mTOR system as well insulin dependent fat accumulation and ubiquitin mediated phagocytosis. Nutrients, although differently adsorbed by intestine and differently metabolized in liver, influence the homeostasis of tissues modulating gene expression and chromatin remodeling, which in turn control the proliferation and differentiation of mesenchymal cells. Adipocytes and osteoblasts derive from Bone Marrow Mesenchymal Pluripotent Cells and their differentiation is also influenced by nutrients and their metabolites.

Cell differentiation is controlled by lipophilic compounds binding nuclear receptors as PPAR $\gamma$ and Myo_D1 modulating cell expression. PPAR $\gamma$ is active in adipocytes and osteoblasts and likely into their mesenchymal progenitors, whereas Myo_D1 controls the expression of cell growth also in osteoblasts. 
Citation: Scotto d'Abusco A, Ammendola S, Cocchiola R, Lopreiato M (2018) Nutritional Screening Tools for Hospitalized Children. Int J Clin Nutr Diet 4: 131. doi: https://doi.org/10.15344/2456-8171/2018/131

Page 9 of 11

Factors that cannot across the cellular membrane, bind surface receptors such as GPR41, GPR43 and similar receptors and transmit the cascade of events that addresses the cell fate. In this picture, microbiota participates in cell differentiation mechanisms producing small and branch chain fatty acids that through the binding to fatty acid receptors, such as GPR41 and GPR43, can influence several pathways.

Further studies are required to enter in the plastic world of the nutrition impact on cell programming and development.

\section{Competing Interests}

The Authors declare that they have no competing interests.

\section{References}

1. Nombela-Arrieta C, Ritz J, Silberstein LE (2011) The elusive nature and function of mesenchymal stem cells. Nat Rev Mol Cell Biol 12: 126-131.

2. Horwitz EM, Le Blanc K, Dominici M, Mueller I, Slaper-Cortenbach I, et al. (2005) Clarification of the nomenclature for MSC: The International Society for Cellular Therapy position statement. Cytotherapy 27: 393-395.

3. Dominici M, Le Blanc K, Mueller I, Slaper-Cortenbach I, Marini F, et al. (2006) Minimal criteria for defining multipotent mesenchymal stroma cells. The International Society for Cellular Therapy position statement. Cytotherapy 8: 315-331.

4. Losson H, Schnekenburger M, Dicato M, Diederich M (2016) Natura Compound Histone Deacetylase Inhibitors (HDACi): Synergy with Inflammatory Signaling Pathway Modulators and Clinical Applications in Cancer. Molecules 21: 608.

5. Li Q, Xia J, Yao Y, Gong DW, Shi H, et al. (2013) Sulforaphane inhibits mammary adipogenesis by targeting adipose mesenchymal stem cells. Breast Cancer Res Treat 141: 317-324.

6. Reginster JY, Deroisy R, Rovati LC, Lee RL, Lejeune E, et al. (2001) Long-term effects of glucosamine sulphate on osteoarthritis progression: a randomised, placebo-controlled clinical trial. Lancet 357: 251-256.

7. Rozendaal RM, Uitterlinden EJ, van Osch GJ, Garling EH, Willemsen SP, et al. (2009) Effect of glucosamine sulphate on joint space narrowing, pain and function in patients with hip osteoarthritis; subgroup analyses of a randomized controlled trial. Osteoarthritis Cartilage 17: 427-432.

8. Jackson CG, Plaas AH, Sandy JD, Hua C, Kim-Rolands S, et al. (2010) The human pharmacokinetics of oral ingestion of glucosamine and chondroitin sulfate taken separately or in combination. Osteoarthritis Cartilage 18: 297 302

9. Uitterlinden EJ, Jahr H, Koevoet JL, Jenniskens YM, Bierma-Zeinstra SM et al. (2006) Glucosamine decreases expression of anabolic and catabolic genes in human osteoarthritic cartilage explants. Osteoarthritis Cartilage 14: $250-257$

10. Varghese $\mathrm{S}$, Theprungsirikul P, Sahani S, Hwang N, Yarema KJ, et al (2007) Glucosamine modulates chondrocyte proliferation, matrix synthesis, and gene expression. Osteoarthritis Cartilage 15: 59-68.

11. Toegel S, Wu SQ, Piana C, Unger FM, Wirth M, et al. (2008) Comparison between chondroprotective effects of glucosamine, curcumin, and diacerein in IL-1beta-stimulated C-28//2 chondrocytes. Osteoarthritis Cartilage 16 1205-1212.

12. Henrotin $\mathrm{Y}$, Mobasheri A, Marty $\mathrm{M}$ (2012) Is there any scientific evidence for the use of glucosamine in the management of human osteoarthritis? Arthritis Res Ther 14: 2012

13. Giordano C, Gallina C, Consalvi V, Scandurra R (1991) Synthesis and properties of D-glucosamine $\mathrm{N}$-peptidyl derivatives as substrate analog inhibitors of papain and cathepsin B. Eur J Med Chem 26: 753-762.

14. Scotto d'Abusco A, Corsi A, Grillo MG, Cicione C, Calamia V, et al. (2008) Effects of intra-articular administration of glucosamine and a peptidylglucosamine derivative in a rabbit model of experimental osteoarthritis: a pilot study. Rheumatol Int 28: 437-443.

15. Veronesi F, Giavaresi G, Maglio M, Scotto d'Abusco A, Politi L, et al. (2017) Chondroprotective activity of $\mathrm{N}$-acetyl phenylalanine glucosamine derivative on knee joint structure and inflammation in a murine model of osteoarthritis. Osteoarthritis Cartilage. 25: 589-599.
16. Scotto d'Abusco A, Calamia V, Cicione C, Grigolo B, Politi L, et al. (2007) Glucosamine affects intracellular signalling through inhibition of mitogenactivated protein kinase phosphorylation in human chondrocytes. Arthritis Res Ther 9: 104

17. Scotto d'Abusco A, Cicione C, Calamia V, Negri R, Giordano C, et al. (2007) Glucosamine and its $\mathrm{N}$-acetyl-phenylalanine derivative prevent TNFalpha-induced transcriptional activation in human chondrocytes. Clin Exp Rheumatol 25: 847-852.

18. Scotto d'Abusco A, Politi L, Giordano C, Scandurra R (2010) A peptidylglucosamine derivative affects IKKa kinase activity in human chondrocytes. Arthritis Res Ther 12: 18

19. Stoppoloni D, Politi L, Leopizzi M, Gaetani S, Guazzo R, et al. (2015) Effect of glucosamine and its peptidyl-derivative on the production of extracellular matrix components by human primary chondrocytes. Osteoarthritis Cartilage 23: 103-113.

20. Pohlig $F$, Ulrich J, Lenze $U$, Mühlhofer $H M$, Harrasser $N$, et al. (2016) Glucosamine sulfate suppresses the expression of matrix metalloproteinase-3 in osteosarcoma cells in vitro. BMC Complement Altern Med 16: 313

21. Luu HH, Kang Q, Park JK, Si W, Luo Q, et al. (2005) An orthotopic model of human osteosarcoma growth and spontaneous pulmonary metastasis. Clin Exp Metastasis 22: 319-329.

22. Rodan SB, Imai Y, Thiede MA, Wesolowski G, Thompson D, et al (1987) Characterization of a human osteosarcoma cell line (Saos-2) with osteoblastic properties. Cancer Res 47: 4961-4966.

23. Leopizzi M, Cocchiola R, Milanetti E, Raimondo D, Politi L, et al. (2017) IKKa inibition by a glucosamine derivative enhances maspin expression in osteosarcoma cell line. Chem Biol Inter 262: 19-28.

24. Kong CS, Kim JA, Eom TK, Kim SK (2010) Phosphorylated glucosamine inhibits adipogenesis in 3T3-L1 adipocytes. J Nutr Biochem 21: 438-443.

25. Ammendola S, Stoppoloni D, Loreto MD, Scotto d'Abusco A (2016) A Nutraceutical Composition decreases CPK levels in Saos-2 cells and in patients with elevated serum levels of this enzyme. J Am Coll Nutr 35: 559567.

26. Weintraub H, Dwarki VJ, Verma I, Davis R, Hollenberg S, et al. (1991) Muscle-specific transcriptional activation by MyoD. Genes Dev 5: 13771386.

27. Douglas TEL, Vandrovcová M, Kročilová N, Keppler JK, Zárubová J, et al. (2018) Application of whey protein isolate in bone regeneration: Effects on growth and osteogenic differentiation of bone-forming cells. J Dairy Sci 101: 28-36.

28. Coker RH, Miller S, Schutzler S, Deutz N, Wolfe RR, et al. (2012) Whey protein and essential amino acids promote the reduction of adipose tissue and increased muscle protein synthesis during caloric restriction-induced weight loss in elderly, obese individuals. Nutr J 11: 105.

29. Bond P (2016) Regulation of mTORC1 by growth factors, energy status, amino acids and mechanical stimuli at a glance. J Int Soc Sports Nutr 13: 8 .

30. Soayfane Z, Tercé F, Cantiello M, Robenek H, Nauze M, et al. (2016) Exposure to dietary lipid leads to rapid production of cytosolic lipid droplets near the brush border membrane. Nutr Metab (Lond) 13: 48.

31. Sabour H, Norouzi Javidan A, Latifi S, Hadian MR, Razavi SE, et al. (2014) Is lipid profile associated with bone mineral density and bone formation in subjects with spinal cord injury? J Osteoporos 2014: 695014.

32. Kim SP, Li Z, Zoch ML, Frey JL, Bowman CE, et al. (2017) Fatty acid oxidation by the osteoblast is required for normal bone acquisition in a sexand diet-dependent manner. JCl Insight 2: 92704

33. Suryawan A, Orellana RA, Nguyen HV, Jeyapalan AS, Fleming JR et al. (2007) Activation by insulin and amino acids of signaling components leading to translation initiation in skeletal muscle of neonatal pigs is developmentally regulated. Am J Physiol Endocrinol Metab. 293: 15971605.

34. Redman LM, Rood J, Anton SD, Champagne C, Smith SR, et al. (2008) Calorie restriction and bone health in young, overweight individuals. Arch Intern Med 168: 1859-1866.

35. Uusi-Rasi K, Sievanen H, Kannus P, Pasanen M, Kukkonen-Harjula K, et al. (2009) Influence of weight reduction on muscle performance and bone mass, structure and metabolism in obese premenopausal women. $J$ Musculoskelet Neuronal Interact 9: 72-80.

36. Upadhyay J, Farr OM, Mantzoros CS (2015) The role of leptin in regulating bone metabolism. Metabolism 64: 105-113.
Int J Clin Nutr Diet

ISSN: 2456-8171
IJCND, an open access journal

Volume 4. 2018. 131 
Citation: Scotto d’Abusco A, Ammendola S, Cocchiola R, Lopreiato M (2018) Nutritional Screening Tools for Hospitalized Children. Int J Clin Nutr Diet 4: 131. doi: https://doi.org/10.15344/2456-8171/2018/131

Page 10 of 11

37. Xu JC, Wu GH, Zhou LL, Yang XJ, Liu JT, et al. (2016) Leptin improves osteoblast differentiation of human bone marrow stroma stem cells. Eur Rev Med Pharmacol Sci 20: 3507-3513

38. Yue R, Zhou BO, Shimada IS, Zhao Z, Morrison SJ, et al. (2016) Leptin Receptor Promotes Adipogenesis and Reduces Osteogenesis by Regulating Mesenchymal Stromal Cells in Adult Bone Marrow. Cell Stem Cell 18:782-796.

39. Goldstone AP, Howard JK, Lord GM, Ghatei MA, Gardiner JV, et al. (2002) Leptin prevents the fall in plasma osteocalcin during starvation in male mice. Biochem Biophys Res Commun 295: 475-481.

40. Conroy R, Girotra M, Shane E, McMahon DJ, Pavlovich KH, et al. (2011) Leptin administration does not prevent the bone mineral metabolism changes induced by weight loss. Metabolism 60: 1222-1226.

41. Lee NK, Sowa H, Hinoi E, Ferron M, Ahn JD, et al. (2007) Endocrine regulation of energy metabolism by the skeleton. Cell 130: 456-469.

42. van de Peppel J, van Leeuwen JP (2014) Vitamin D and gene networks in human osteoblasts. Front Physiol 5: 137.

43. Abbas MA (2017) Physiological functions of Vitamin D in adipose tissue. $J$ Steroid Biochem Mol Biol 165: 369-381.

44. Booth SL (2012) Vitamin K: food composition and dietary intakes. Food Nutr Res.

45. Soeta S, Higuchi M, Yoshimura I, Itoh R, Kimura N, et al. (2010) Effects of vitamin $\mathrm{E}$ on the osteoblast differentiation. J Vet Med Sci 72: 951-957.

46. Alcala M, Calderon-Dominguez M, Serra D, Herrero L, Ramos MP, et al (2017) Short-term vitamin $E$ treatment impairs reactive oxygen species signaling required for adipose tissue expansion, resulting in fatty liver and insulin resistance in obese mice. PLoS One 12: e0186579.

47. Lind T, Sundqvist A, Hu L, Pejler G, Andersson G, et al. (2013) Vitamin A is a negative regulator of osteoblast mineralization. PLoS One 8: e82388.

48. Frey SK, Vogel S (2011) Vitamin A metabolism and adipose tissue biology. Nutrients 3: 27-39.

49. Moon HJ, Ko WK, Jung MS, Kim JH, Lee WJ, et al. (2013) Coenzyme q10 regulates osteoclast and osteoblast differentiation. J Food Sci 78: 785-891.

50. Xu Z, Huo J, Ding X, Yang M, Li L, et al. (2017) Coenzyme Q10 Improves Lipid Metabolism and Ameliorates Obesity by Regulating CaMKII-Mediated PDE4 Inhibition. Sci Rep 7: 8253.

51. Lv S, Wu L, Cheng P, Yu J, Zhang A, et al. (2010) Correlation of obesity and osteoporosis: Effect of free fatty acids on bone marrow-derived mesenchymal stem cell differentiation. Exp Ther Med 1: 603-610.

52. Lucas S, Omata Y, Hofmann J, Böttcher M, Iljazovic A, et al. (2018) Shortchain fatty acids regulate systemic bone mass and protect from pathological bone loss. Nat Comm 9: 55 .

53. Zou J, Chassaing B, Singh V, Pellizzon M, Ricci M, et al. (2018) FiberMediated Nourishment of Gut Microbiota Protects against Diet-Induced Obesity by Restoring IL-22-Mediated Colonic Health. Cell Host Microbe 23 41-53.

54. Kushwaha P, Wolfgang MJ, Riddle RC (2017) Fatty acid metabolism by the osteoblast. Bone 8756-3282: 30318-30316.

55. Casado-Díaz A, Santiago-Mora R, Dorado G, Quesada-Gómez JM (2013) The omega- 6 arachidonic fatty acid, but not the omega- 3 fatty acids, inhibits osteoblastogenesis and induces adipogenesis of human mesenchymal stem cells: potential implication in osteoporosis. Osteoporos Int 24: 1647 1661.

56. Ing SW, Belury MA (2011) Impact of conjugated linoleic acid on bone physiology: proposed mechanism involving inhibition of adipogenesis. Nut Rev 69: 123-131.

57. Kim J, Park Y, Lee SH, Park Y (2013) Trans-10, cis-12 conjugated linoleic acid promotes bone formation by inhibiting adipogenesis by peroxisome proliferator activated receptor-y-dependent mechanisms and by directly enhancing osteoblastogenesis from bone marrow mesenchymal stem cells. J Nutr Biochem 24: 672-679.

58. Poulsen LI, Siersbæk M, Mandrup S (2012) PPARs: fatty acid sensors controlling metabolism. Semin Cell Dev Biol 23: 631-639.

59. Bojin FM, Gruia AT, Cristea MI, Ordodi VL, Paunescu V, et al. (2012) Adipocytes differentiated in vitro from rat mesenchymal stem cells lack essential free fatty acids compared to adult adipocytes. Stem Cells Dev 21: $507-512$
60. Fillmore N, Huqi A, Jaswal JS, Mori J, Paulin R, et al. (2015) Effect of fatty acids on human bone marrow mesenchymal stem cell energy metabolism and survival. PLoS One 10: e0120257.

61. Iván J, Major E, Sipos A, Kovács K, Horváth D, et al. (2017) The ShortChain Fatty Acid Propionate inhibits adipogenic differentiation of human chorion-derived mesenchymal stem cells through the Free Fatty Acid Receptor 2. Stem Cells Dev 26: 1724-1733.

62. Xu Y, Hammerick KE, James AW, Carre AL, Leucht $P$, et al. (2009) Inhibition of histone deacetylase activity in reduced oxygen environment enhances the osteogenesis of mouse adipose-derived stromal cells. Tissue Eng Part A 15: 3697-3707.

63. García-Martínez O, De Luna-Bertos E, Ramos-Torrecillas J, Ruiz C, Milia $\mathrm{E}$, et al. (2016) Phenolic compounds in extra virgin olive oil stimulate human osteoblastic cell proliferation. PLoS ONE 11: e0150045.

64. Lin LZ, Chen HH, Lei ZX, Li YR, Zhou CH, et al. (2018) Rosmarinic acid protects on rat bone marrow mesenchymal stem cells from hydrogen peroxide-induced apoptosis. J Asian Nat Prod Res 28: 1-11.

65. Wang L, Li L, Ran X, Long M, Zhang M, et al. (2013) Ellagic Acid Reduces Adipogenesis through Inhibition of Differentiation-Prevention of the Induction of Rb Phosphorylation in 3T3-L1 Adipocytes. Evid Based Complement Alternat Med 2013: 287534.

66. Spilmont M, Léotoing L, Davicco M-J, Lebecque $P$, Miot-Noirault E, et al. (2015) Pomegranate peel extract prevents bone loss in a preclinical model of osteoporosis and stimulates osteoblastic differentiation in vitro. Nutrients 7: $9265-9284$.

67. Al-Obaidi MM, Al-Bayaty $\mathrm{FH}, \mathrm{Al}$ Batran R, Hussaini J, Khor $\mathrm{GH}$, et al (2014) Impact of Ellagic acid in bone formation after tooth extraction: an experimental study on diabetic rats. Scientific World Journal 2014: 908098.

68. Li C, Yang Z, Li Z, Ma Y, Zhang L, et al. (2011) Maslinic acid suppresses osteoclastogenesis and prevents ovariectomy-induced bone loss by regulating RANKL-mediated NF-kB and MAPK signaling pathways. J Bone Min Res 26: 644-656.

69. Pérez-Jiménez A, Rufino-Palomares EE, Fernández-Gallego N, OrtuñoCostela MC, Reyes-Zurita FJ, et al. (2016) Target molecules in 3T3-L1 adipocytes differentiation are regulated by maslinic acid, a natural triterpene from Olea europaea. Phytomedicine 23: 1301-1311.

70. Urban K, Höhling HJ, Lüttenberg B, Szuwart T, Plate U, et al. (2012) An in vitro study of osteoblast vitality influenced by the vitamins $C$ and $E$. Head Face Med 8: 25

71. Aghajanian P, Hall S, Wongworawat MD, Mohan S (2015) The Roles and Mechanisms of Actions of Vitamin C in Bone: New Developments. J Bone Miner Res 30: 1945-1955.

72. Zhang P, Li J, Qi Y, Zou Y, Liu L, et al. (2016) Vitamin C promotes the proliferation of human adipose-derived stem cells via p53-p21 pathway. Organogenesis 12: 143-151.

73. Kang KK, Lee EJ, Kim YD, Chung MJ, Kim JY, et al. (2017) Vitamin C Improves Therapeutic Effects of Adipose-derived Stem Cell Transplantation in Mouse Tendonitis Model. In Vivo 31: 343-348.

74. Park JK, Lee EM, Kim AY, Lee EJ, Min CW, et al. (2012) Vitamin C deficiency accelerates bone loss inducing an increase in PPAR-y expression in SMP30 knockout mice. Int J Exp Pathol 93: 332-340.

75. Crovesy L, Ostrowski M, Ferreira DMTP, Rosado EL, Soares-Mota M, et al. (2017) Effect of Lactobacillus on body weight and body fat in overweight subjects: a systematic review of randomized controlled clinical trials. Int $\mathrm{J}$ Obes (Lond) 41: 1607-1614

76. Mekkes MC, Weenen TC, Brummer RJ, Claassen E (2014) The development of probiotico treatment in obesity: a review. Benef Microbes 5: 19-28.

77. Kim M, Kim M, Kang M, Yoo HJ, Kim MS, et al. (2017) Effects of weight loss using supplementation with Lactobacillus strains on body fat and mediumchain acylcarnitines in overweight individuals. Food Funct 8: 250-261.

78. Zhang $Y$, Zhang $H$ (2013) The effect of probiotics on lipid metabolism Endocrinology and Metabolism. Lipid Metabolism ed Rodrigo Valenzuela Baez, chapt 17

79. Takemura N, Okubo T, Sonoyama K (2010) Lactobacillus plantarum strain No. 14 reduces adipocyte size in mice fed high-fat diet. Exp Biol Med (Maywood) 235: 849-856.

80. Fabersani E, Abeijon-Mukdsi MC, Ross R, Medina R, González S, et al (2017) Specific Strains of Lactic Acid Bacteria Differentially Modulate the Profile of Adipokines In Vitro. Front Immunol 8: 266. 
Citation: Scotto d'Abusco A, Ammendola S, Cocchiola R, Lopreiato M (2018) Nutritional Screening Tools for Hospitalized Children. Int J Clin Nutr Diet 4: 131. doi: https://doi.org/10.15344/2456-8171/2018/131

Page 11 of 11

81. Narva M, Rissanen J, Halleen J, Vapaatalo $\mathrm{H}$, Väänänen $\mathrm{K}$, et al. (2007) Effects of Bioactive Peptide, Valyl-Prolyl-Proline (VPP), and Lactobacillus helveticus Fermented Milk Containing VPP on Bone Loss in Ovariectomized Rats. Ann Nutr Metab 51: 65-74.

82. Gonzalez-Gonzalez C, Gibson T, Jauregi P (2013) Novel probioticfermented milk with angiotensin l-converting enzyme inhibitory peptides produced by Bifidobacterium bifidum MF 20/5. Int J Food Microbiol 167: 131-137.

83. Collins FL, Rios-Arce ND, Schepper JD, Parameswaran N, McCabe LR, et al. (2017) The Potential of Probiotics as a Therapy for Osteoporosis. Microbiol Spectr.

84. Niehage C, Steenblock C, Pursche T, Bornhäuser M, Corbeil D, et al. (2011) The cell surface proteome of human mesenchymal stromal cells. PLoS One 6: e20399.

85. Shin JH, Jeon HJ, Park J, Chang MS (2016) Epigallocatechin-3gallate prevents oxidative stress-induced cellular senescence in human mesenchymal stem cells via Nrf2. Int J Mol Med 38: 1075-1082.

86. Panche AN, Diwan AD, Chandra SR (2016) Flavonoids: an overview. J Nutr Sci 5: e47.

87. Ammendola S, Cocchiola R, Lopreiato M, Politi L, Scandurra R, et al (2018) Olive fruit blends modulate lipid-sensing nuclear receptor PPARy, cell survival and oxidative stress response in human osteoblast cells. J Am Coll Nutr 13: 1-9.

88. Ammendola S, Loreto MD, Scotto d'Abusco A (2017) Modulatory Effects of a Nutraceutical Supplement on Saos-2 Cells Reveal Its Phlebotonic Activity. J Am Coll Nutr 36: 268-272.

89. García-Martínez O, De Luna-Bertos E, Ramos-Torrecillas J, Ruiz C, Milia E, et al. (2016) Phenolic Compounds in Extra Virgin Olive Oil Stimulate Human Osteoblastic Cell Proliferation. PLoS One 11: e0150045.

90. Chang KL, Hu YC, Hsieh BS, Cheng HL, Hsu HW, et al. (2013) Combined effect of soy isoflavones and vitamin D3 on bone loss in ovariectomized rats. Nutrition 29: 250-257.

91. Xie Y, Li X, Xu J, Jiang Q, Xie H, et al. (2017) Two phenolic antioxidants in Suoyang enhance viability of $\cdot \mathrm{OH}$-damaged mesenchymal stem cells: comparison and mechanistic chemistry. Chem Cent J 11: 84.

92. Lin H, Wei B, Li G, Zheng J, Sun J, et al. (2014) Sulforaphane reverses glucocorticoid-induced apoptosis in osteoblastic cells through regulation of the Nrf2 pathway. Drug Des Devel Ther 8: 973-82.

93. Zhang HQ, Chen SY, Wang AS, Yao AJ, Fu JF, et al. (2016) Sulforaphane induces adipocyte browning and promotes glucose and lipid utilization. Mol Nutr Food Res 60: 2185-2197.

94. Ding G, Zhao J, Jiang D (2016) Allicin inhibits oxidative stress-induced mitochondrial dysfunction and apoptosis by promoting PI3K/AKT and CREB/ERK signaling in osteoblast cells. Exp Ther Med 11: 2553-2560.

95. Lee MS, Kim IH, Kim CT, Kim Y (2011) Reduction of body weight by dietary garlic is associated with an increase of uncoupling protein mRNA expression and activation of AMP- activated protein kinase in diet-induced obese mice. J Nutr 141: 1947-1953.

96. Kimura S, Tung YC, Pan MH, Su NW, Lai YD, et al. (2017) Black garlic: a critical review of its production, bioactivity, and application. J Food Drug Analysis 25: 62-70

97. Linnewiel-Hermoni K, Motro Y, Miller Y, Levy J, Sharoni Y, et al. (2014) Carotenoid derivatives inhibit nuclear factor kappa B activity in bone and cancer cells by targeting key thiol groups. Free Radic Biol Med 75: 105120.

98. Tominari T, Matsumoto C, Watanabe K, Hirata M, Grundler Florian MW, et al. (2017) Lutein, a carotenoid, suppresses osteoclastic bone resorption and stimulates bone formation in cultures. Bios Biotech Bioch 81: 302-306.

99. Tian Y, Kijlstra A, Renes J, Wabitsch M, Webers Carroll AB, et al. (2015) Lutein leads to a decrease of factor $d$ secretion by cultured mature human adipocytes. J Ophthal 2015: 430741.

This article was originally published in a special issue

Functional Foods and Nutraceuticals: Their Role in Disease Prevention

\section{Handled by Editors:}

Prof. Luciana Mosca (Lead Specail Issue Editor)

Department of Biochemical Sciences

University of Rome "La Sapienza"

Italy

Dr. Ilaria Peluso

Food and Nutrition Center

Agricultural Research Council (CRA-NUT)

Italy

Dr. Alessia Baseggio Conrado

Photobiology Unit at the Cancer Division

University of Dundee

United Kingdom

Dr. Anna Scotto D'abusco

Department of Biochemical Sciences

Sapienza University of Rome

Italy 